http://jmscr.igmpublication.org/home/

ISSN (e)-2347-176x ISSN (p) 2455-0450

crossref DOI: https://dx.doi.org/10.18535/jmscr/v7i12.116

Journal Of Medical Science And Clinical Research

\title{
Radial Inclination and Palmar tilt as Risk Factors for Kienböck's Disease
}

\author{
Authors \\ Ajaz Ahmad Bhat ${ }^{1}$, Zubair Ringshawl ${ }^{2}$, Suhail Wani $^{3}$ \\ ${ }^{1}$ Medical Officer, Department of Health, J\&K \\ ${ }^{2,3}$ Postgraduate Scholars, Orthopaedic Department, GMC Srinagar
}

\begin{abstract}
Radial inclination angle (RIA) and palmar tilt (PT) of distal articular surface of radius, are anatomical factors that influence force transmission across the wrist and load transfer to the lunate. The purpose of this study is to evaluate the relationship between these parameters and Kienböck's disease.

We measured and compared RIA and PT in standard posteroanterior and lateral wrist x-rays of 50 patients with Kienböck's disease and 55 controls. The mean RIA was $26.5^{\circ}$ in Kienböck's disease patients and $24.0^{\circ}$ in the control group $(P=0.002)$. The mean $P T$ was $12.5^{\circ}$ and $10.4^{\circ}$ for patients and controls, respectively $(P=0.005)$. All of these differences were statistically significant. We concluded that there is an etiological association between higher degrees of RIA and PT with Kienböck's disease.
\end{abstract}

\section{Introduction}

In 1910, Robert Kienböck, a Viennese radiologist, reported a series of 16 cases of traumatic malacia of the lunate ${ }^{1}$. Although others had described similar anatomic findings in cadaveric specimens, Kienbocks was the first clinical report of osteonecrosis of the lunate. Controversy still exists about the etiology of the disease despite numerous investigations. Negative ulnar variance, first identified as a factor by Hulten ${ }^{2}$ in 1928, was present in $78 \%$ of his patients with Kienbcks disease, but in only $23 \%$ of the general population. Hulten suggested that a short distal ulna led to increased force transmission across the radiolunate articulation, contributing to an increased risk of osteonecrosis. However, D'Hoore et $\mathrm{al}^{3}$ found no statistically significant difference in ulnar variance when they compared 125 normal wrists with 52 wrists in patients with Kienbock's disease. Several investigators from
$\operatorname{Japan}^{4,5}$ have noted that negative ulnar variance occurs with equal frequency in patients with Kienbock's disease and in the general population. Among other various anatomical features that were postulated as the risk factors for lunatomalacia ${ }^{5,6}$, those that are related to the biomechanic of force transmission across the wrist and load transfer to the lunate, are more challenging and thus more attractive ${ }^{7}$. As per the biomechanical analyses, radial inclination angle (RIA) and palmar tilt (PT) of distal radial articular surface, have apparent impact on the load transfer to the lunate ${ }^{7,8}$. A flattened radial inclination may predispose to Kienbcks disease ${ }^{5,9}$. Nevertheless, different and even paradoxical results were reported about the relationship between these parameters and Kienböck's disease ${ }^{9-13}$. The purpose of this study was to determine the RIA and PT as possible anatomical risk factors for Kienböck's disease 


\section{Patients and Methods}

This study was conducted in the Department of Orthopaedics, Government Medical College, Srinagar between August 2016 and January 2019. Wrist radiographs of patients diagnosed with Kienböck's disease, based on typical $\mathrm{x}$-ray and magnetic resonance imaging (Figure $\mathrm{A}$ and $\mathrm{B}$ ). The diagnostic criteria laid by the Lichtman ${ }^{14}$ were used to classify patients into different stages:-

Stage I: linear or compression fracture of lunate in plain radiograph or low signal intensity on MRI in the absence of x-ray changes.

Stage II: sclerosis and density changes.

Stage IIIA: collapse or fragmentation of lunate without carpal collapse.

Stage IIIB: Stage IIIA with carpal collapse.

Stage IV: All the findings of stage III plus generalized degenerative changes within the carpus.

There were no stage I patients diagnosed during this period and those patients with stage IV disease were excluded from the study to avoid interference of osteoarthritic changes with measurements.

The posteroanterior wrist $\mathrm{x}$-ray was considered acceptable when the cortical margin of the extensor carpi ulnaris groove was radial to the ulnar styloid ${ }^{15}$, and this was true for the lateral view when the palmar aspect of pisiform located between the capitate and the volar surface of distal scaphoid $^{16}$.

Wrist x-rays of 50 patients (40 males, 10 females) between 18 to 45 years (mean age, 26.4 years), were included in this study. Of these patients, 13 were stage II, 25 stage IIIA, and 12 stage IIIB. Majority of patients were in stage IIIA.

The control group consisted of radiographs from the uninjured wrist of 55 wrist trauma patients (40 males and 15 females between 16 to 55 years; mean 28.2), that were taken in standard manner described by Palmer and colleagues ${ }^{17}$. History about any old trauma, pain of this wrist or generalized bone disorder were taken from control group. There was no significant difference between patients and controls according to age ( $\mathrm{P}$ $=0.21$ ).

Radiologic parameters that we evaluated in this study were RIA and PT. Angulation of distal articular surface of radius was considered in relation to the long axis of bone in posteroanterior view of wrist to measure the RIA, PT was determined by a line connecting the distal points of dorsal and volar rims of radius, in relation to another line perpendicular to the long axis of bone in lateral view of wrist ${ }^{18}$.

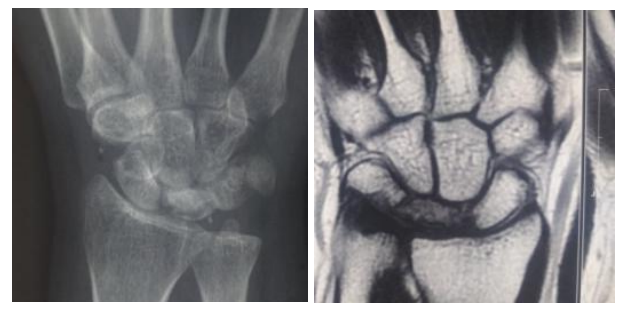

Figure. (A) A posteroanterior wrist radiograph displaying sclerosis and fragmentation of the lunate. (B) The corresponding T1-weighted coronal image MRI shows a low signal intensity necrotic lunate.

\section{Results}

Based on our measurements, the mean RIA was 26.5 in Kienböck's disease patients (range, $20^{\circ}$ $34^{\circ}$ ), and $24.0^{\circ}$ in controls (range, $12^{\circ}-30^{\circ}$ ). This difference was statistically significant $(\mathrm{P}=0.002)$. This study has also revealed that the mean PT was $12.5^{\circ}$ (range, $6^{\circ}-20^{\circ}$ ) and $10.4\left(\right.$ range, $0^{\circ}-15^{\circ}$ ) in Kienböck's disease patients and controls, respectively. This difference was also statistically significant $(\mathrm{P}=.005)$.

\section{Discussion}

Mir and colleagues ${ }^{19}$ showed steeper radial inclination in patients with Kienböck's disease. Watanabe and colleagues, ${ }^{9}$ as well as Tsumura and colleagues, ${ }^{10,11}$ also showed a direct relationship between radial inclination and force transmission to the lunate in biomechanical studies; these findings were supported by several clinical studies ${ }^{7,20-22}$. However, Mirabello and colleagues $^{6}$, and Tsuge and Nakamura ${ }^{5}$ demonstrated that RIA is flatter in patients with Kienböck's disease. Experimental studies also 
showed increased lunate strain by decreasing radial inclination, but no clinical correlation was demonstrated ${ }^{11,12}$. Davood Jafari et $\mathrm{al}^{23}$, demonstrated thst RIA was steeper in Kienböck's patients as compared to controls in their study which suggests higher RIA may be a risk factor for in Kienböck's disease. In our study, RIA was significantly steeper in patients with Kienböck's disease, compared with controls. This suggests that there may be an etiological association between high RIA and Kienböck's disease.

Lamas and colleagues ${ }^{7}$ proposed that lunate is under excess load, especially in dorsal pole due to palmar facing articular surface of radius, and suggested that reduction of PT decompressed the lunate in sagittal plane and increased radiolunate space. Nevertheless, according to Tsuge and Nakamura, ${ }^{5}$ PT was not markedly higher in lunatomalacia. Based on the results of our study, PT of distal articular surface of radius was markedly higher in Kienböck's patients, compared with controls. Greater PT may be a risk factor for this disease.

\section{Conclusion}

We conclude that steeper RIA and PT may be an etiological factor for Kienböck's disease.

\section{References}

1. Kienbock R; Peltier L (trans-ed): Concerning traumatic malacia of the lunate and its consequences: Degeneration and compression fractures [classic reprint]. Clin Orthop 1980;149:4-8.

2. Hulten $\mathrm{O}$ : ber anatomische Variationen der Handgelenkknochen. Acta Radiol Scand 1928;9:155-168.

3. D'Hoore K, DeSmet L, Verellen K, Vral J, Fabry G: Negative ulnar variance is not a risk factor for Kienbcks disease. J Hand Surg [Am] 1994;19:229-231.

4. Nakamura R, Imaeda T, Miura T: Radial shortening for Kienbcks disease: Factors affecting the operative result. J Hand Surg [Br] 1990;15:40-45.
5. Tsuge S, Nakamura R: Anatomical risk factors for Kienbcks disease. J Hand Surg [Br] 1993;18:70-75.

6. Mirabello SC, Rosental DI, Smith RJ. Correlation of clinical and radiographic findings in Kienböck's disease. J Hand Surg Am. 1987;12(6):1049-1054.

7. Lamas C, Mir X, Llusà $M$, Navarro A. Dorsolateral biplane closing radial osteotomy in zero variant cases of Kienböck's disease. J Hand Surg Am. 2000;25(4):700-709.

8. Solgaard S. Fuction after distal radius fracture. Acta Orthop Scand. 1988;59(1):39-42.

9. Watanabe K, Nakamura R, Horii E, Miura $\mathrm{T}$ : Biomechanical analysis of radial wedge osteotomy for the treatment of Kienbcks disease. J Hand Surg [Am] 1993;18:686690.

10. Tsumura H, Himeno S, Kojima T, Kido M. Biomechanical analysis of Kienböck's disease; its cause and treatments. Seikeigeka. 1982;33:1400-1402.

11. Tsumura H, Himeno S, An KN, Cooney WP, Chao EYS. Biomechanical analysis of Kienböck's disease. Orthop Trans. 1987;11:327.

12. Werner FW, Palmer AK. Biomechanical evaluation of operative procedures to treat Kienböck's disease. Hand Clin. 1993;9(3):431-443.

13. Kam B, Topper SM, McLoughlin S, Liu Q. Wedge osteotomies of the radius for Kienböck's disease: a biomechanical analysis. J Hand Surg Am. 2002;27(1):3742.

14. Lichtman DM, Mack GR, MacDonald RI, Gunther SF, Wilson JN: Kienbcks disease: The role of silicone replacement arthroplasty. J Bone Joint Surg Am 1977;59:899-908.

15. Levis CM, Yang Z, Gilula LA. Validation of the extensor carpi ulnaris groove as a predictor for the recognition of standard 
posteroanterior radiographs of the wrist. $\mathrm{J}$ Hand Surg Am. 2002;27(2):252-257.

16. Yang Z, Mann FA, Gilula LA, Haerr C, Larsen CF. Scaphopisocapitate alignment: criterion to establish a neutral lateral view of the wrist. Radiology. 1997;205(3):865869.

17. Palmer AK, Glisson RR, Werner FW. Ulnar variance determination. J Hand Surg Am. 1982;7(4):376-379.

18. Mann FA, Wilson AJ. Gilula LA. Radiographic evaluation of the wrist: what does the hand surgeon want to know? Radiology. 1992;184(1):15-24.

19. Mir X, Liusa M, Arcalis A, Nardi J. Relationship between ulnar inclination of the distal radial joint and Kienböck's disease. Rev Esp Cir Mano. 1992;19:9394.

20. Nakamura R, Tsuge S, Watanabe $K$, Tsunoda K. Radial wedge osteotomy for Kienböck's disease. J Bone Joint Surg Am. 1991;73(9):1391-1396.

21. Soejima O, Lida H, Komine S, Kikuta T, Naito M. Lateral closing wedge osteotomy of the distal radius for advanced stages of Kienböck's. J Hand Surg Am. 2002;27(1):31-36.

22. Miura H, Sugioka Y. Radial closing wedge osteotomy for Kienböck's disease. J Hand Surg Am. 1996;21(6):1029-1034.

23. Davood Jafari, MD, Hooman Shariatzadeh, MD, Farid Najd Mazhar, MD, Mohammad H. Ghahremani, MD, and Alireza Jalili, MD. Radial inclination and palmar tilt as risk factors for Kienböck's disease. Am J Orthop. 2012;41(11):E145-146. 